\title{
Earthquake Vulnerability Assessment using Expert-based Approach in GIS
}

\author{
${ }^{1}$ Ratiranjan Jena, The Centre for Advanced \\ Modelling and Geospatial Information \\ Systems (CAMGIS), Faculty of Engineering \\ and Information Technology, University of \\ Technology Sydney, NSW 2007, Australia
}

\author{
${ }^{2}$ Biswajeet Pradhan*The Centre for Advanced \\ Modelling and Geospatial Information \\ Systems (CAMGIS), Faculty of Engineering \\ and Information Technology, University of \\ Technology Sydney, NSW 2007, Australia
}

*Correspondence: Biswajeet Pradhan*, Biswajeet.Pradhan@uts.edu.au

\begin{abstract}
Several techniques of earthquake vulnerability assessment exist for the evaluation of social, economic and buildings vulnerability that has been carried out to investigate their suitability in the application of earthquake risk assessment. The primary challenge is the prediction of earthquakes that is almost seemingly impossible in the current time. The main concern is mitigation and preparedness, which is dominant for the human, animals, and environment. However, exposed assets and the determination of their fragilities/vulnerabilities are essential and will be challenging in the future for the viability and reliability during the assessment of rapid loss. Therefore, this study proposes an expert's decision-based approach for the assessment of earthquake vulnerability in Banda Aceh city, Indonesia that could help in future risk assessment on a city scale. It was analysed that the proposed method adequately satisfies all the necessary criteria that can be involved in earthquake vulnerability assessment in Banda Aceh city to reduce the earthquake impacts. The results shows that the proposed method is good for city-scale earthquake vulnerability assessment with significant consistency ratio of 0.04 . This research observes the current practices involved in regional and urban earthquake vulnerability assessment.
\end{abstract}

Keywords: Earthquake, Vulnerability, GIS, Expert's based approach

\section{INTRODUCTION}

Indonesia is the country encompasses with a number of islands falling under the seismic zone of Java Sumatra subduction zone, which is one of the most seismically active regions on the planet Earth. The country's territory is covered with over $18000 \mathrm{~km}$ of a tectonic plate boundary, which is almost double of the fault length of Japan or Papua New Guinea plate boundary (Figure 1). This plate boundary characterised with the Great Sumatran Fault, at $1900 \mathrm{~km}$ length, which is almost 50 per cent of the North Anatolian and San Andreas faults; a $6000 \mathrm{~km}$ length of convergent plate margin, extending from off Sumatra to the Banda Sea which experienced the second largest earthquake of megathrust origin $[1,2,6]$ and one of the largest intraslab earthquakes in the world [6]. It is also characterised by the subduction zones with highest-curvature in world tectonics. Banda Arc is curving up to $1808 \mathrm{~km}$ in $2200 \mathrm{~km}$ of total length. Indonesia is characterised with almost 127 active volcanoes, which is higher than any other Asia-Pacific country. Three of the deadliest eruptions experienced in Indonesia in human history: Ref. [1] explained that 1257 Rinjani (Volcanic Explosivity Index) VEI 7, unknown damages and fatalities experienced; Ref [2, 3, 5] described that 1815 Tambora experienced VEI 7, 71000 fatalities while Self \& Rampino (1981) demonstrated that 1883 Krakatau experienced VEI 6, 36000 fatalities. These volcanic activities are associated with earthquakes. The tectonic environment of Indonesia is characterised with some remarkable features of divergent double subduction zones of the Molucca Sea Plate resulted due to the arc-arc collision $[2,3]$. The continental lithosphere subducted in the Banda Sea producing the arc-continent collision [3, 4]. The youngest orogenies can be found in Indonesia along the Timor-Tanimbar part located in Banda Arc $[4,5]$; and characterised with mud volcanoes in some areas in the arc [6]. The whole tectonics we described above is the main source of plate movement and the experienced earthquakes. 
The majority of buildings in Northern Sumatra of Indonesia had characterised by unreinforced masonry infilled walls. The masonry materials used in these buildings were consistently of the similar type; having average thickness of $50 \mathrm{~mm}$ [4]. Hollow clay bricks as well as concrete blocks of equal thickness was applied to all the buildings in the city. These buildings suffered a lot because of earthquakes and tsunami wave that causes shear failures if the pressure hit the building walls perpendicularly [6]. Non-planned, both low and high rise reinforced concrete buildings are extremely vulnerable which may cause partial or full collapse because of earthquake ground shaking or tsunami pressure $[4,5]$. Columns of very old buildings are also vulnerable to the earthquake-generated forces because of strong ground shaking that may lead to flexural failures of building walls if directly hitting the mid-heights.

Generally, in Indonesia, earthquakes and tsunami incorporate a potent threat to society and a large vulnerable population [1]. Therefore, it is quite important to make decisions with very accurate and precise mapping by disaster managers that should be analysed by the best knowledge of Earth sciences. Substantial progress has been observed in current years in providing the best approaches of Earth science that is capable of support disaster risk reduction. However, Indonesia has been experienced a large set of earthquakes as it is coming under the seismic zone. Therefore, the study aimed at projecting the vulnerable areas due to the earthquake in the city of Banda Aceh, estimating the expected losses as well as distribution according to earthquake intensity and time of the day. This paper is valuable for researchers, scientists, and seismologist and can be used as a strategy for the future earthquake risk assessment in Indonesia. The results obtained from this study is because of the novel and creative methodological approach and applied indicators. The proposed method can be used for any study area by simply modifying the applied indicators.

\section{STUDY AREA}

Banda Aceh is the capital city of Aceh province in Indonesia that can be found on soft and unconsolidated thick alluvium sediments (soft soil) [1]. The capital city Banda Aceh in Aceh province was hit by the megathrust earthquake of $9.3 \mathrm{MW}$ in 2004 that caused severe damages to old buildings as well as reinforced concrete (RC) buildings, which is a major issue in current times [2]. The response spectral acceleration that was estimated was up to $0.8 \mathrm{~g}$ [3]. The study area is characterised by a structural design with improper planning of the city buildings. Therefore, improper design of large buildings decreases the resistance power and building performance of Banda Aceh city because of the earthquake $(\mathrm{Mw}=9.3)$ and tsunami during December 2004. Overall 200,000 people had lost lives and loss of buildings, lifelines, infrastructures as well as the environmental damages have been experienced [7, 8]. All the residential buildings and households along the coastal region were destroyed because of earthquake and tsunami. Roads and embankments of the Banda Aceh city were identified to be collapsed and damaged because of the lateral spread of liquefaction.capacity and that causes major destruction due to high magnitude earthquakes. The study area is characterised by quaternary sedimentary rocks and unconsolidated sediments. Catastrophic damages have been experienced in coastal areas.

\section{DATA}

Tectonic and geological datasets were collected and processed with GIS software to generate intensity maps for different earthquake scenarios. Buildings data, population data, educated people and building quality was used to perform the vulnerability assessment. These data were acquired and analysed to determine the density and distance from the populated places, which affect the total vulnerability. An inventory map that was used to carried out the analysis over 62,000 buildings by considering the buildings without focusing the categories with different fragility rates. The datasets were combined and analysed to estimate the percentage of areas are under the vulnerability zones based on predicted results.

\section{METHODOLOGY}

The most extended form of AHP is the ANP that typically considers a large number of element feedbacks; independence can be found within and between the levels and it considers the impact of each element on the alternative criteria. Generally, the ANP is a properly planned network relationship, however, in the case of AHP it ignores interdependency. Therefore, the main steps for applying the ANP methodology are described in (Figure 1, 2, 3) [4, 9, 10].

\section{A. Step $A$}

It is quite important to understand the problem structure and model construction. Firstly, an illustration of the importance of factors were obtained based on several criteria. The pairwise comparison and priority vectors are the common processes in both ANP and AHP that considers each element impacts on others $[11,12]$. 


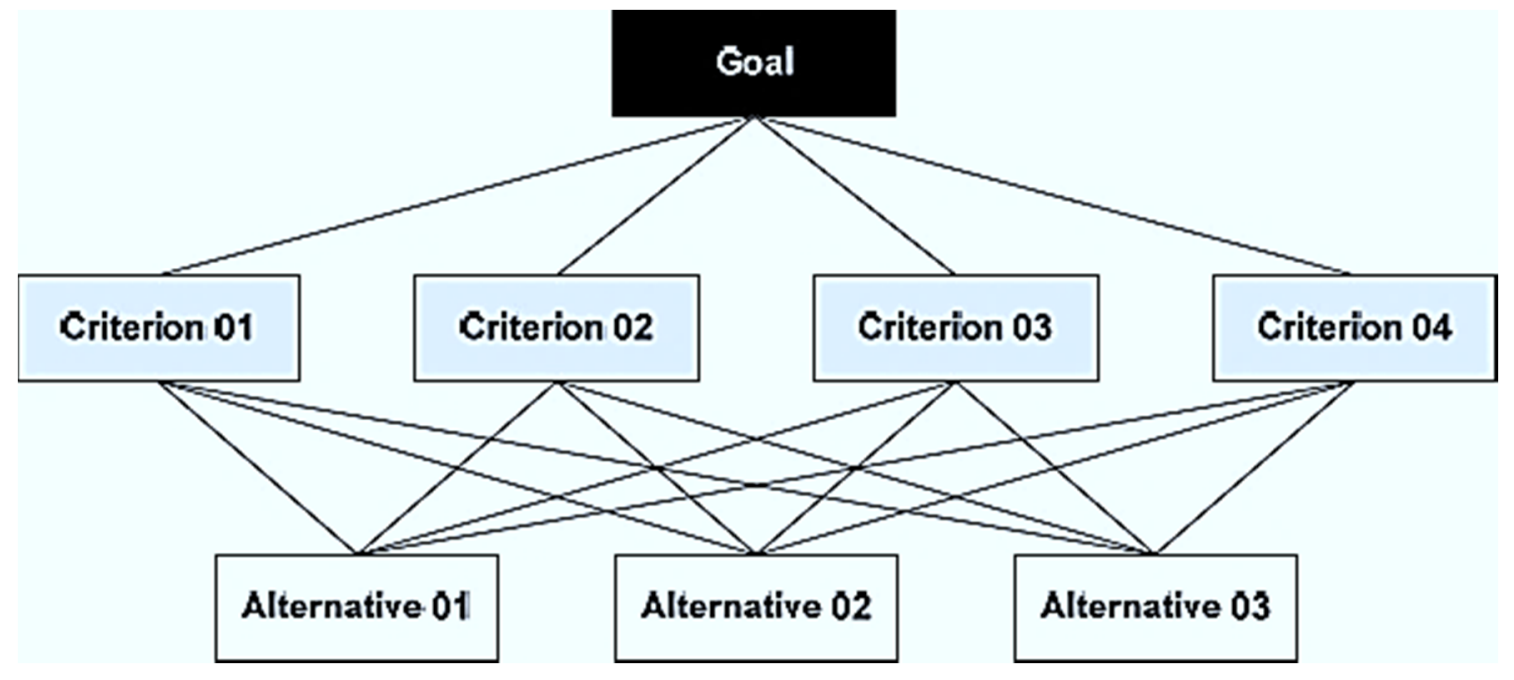

Figure 1. ANP architecture in three stages [4].

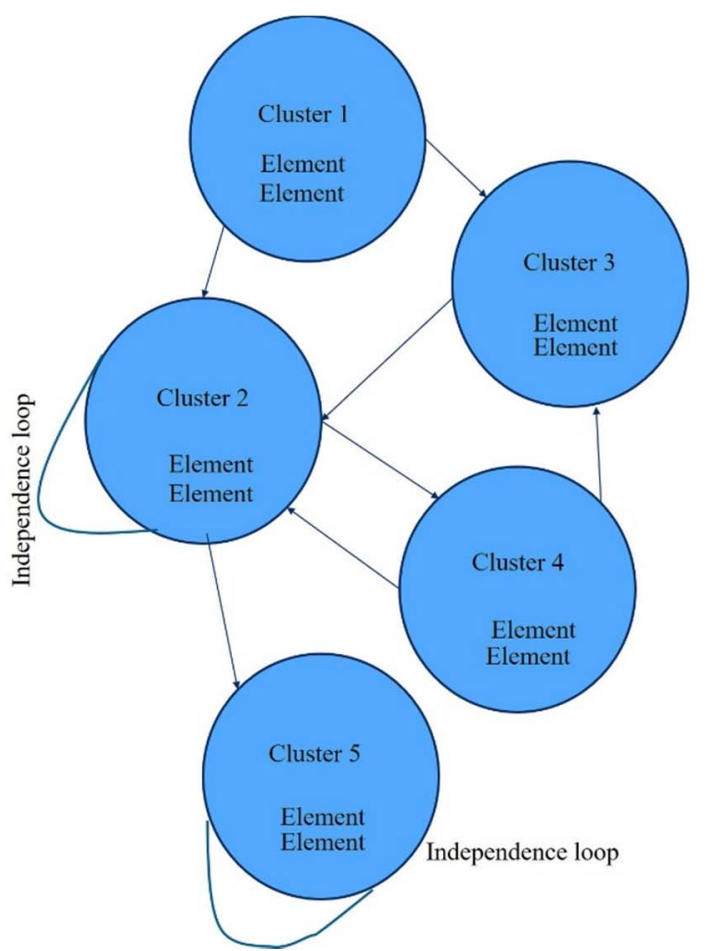

Figure 2. Represents the super matrix for ANP approach [4, 12, 13].

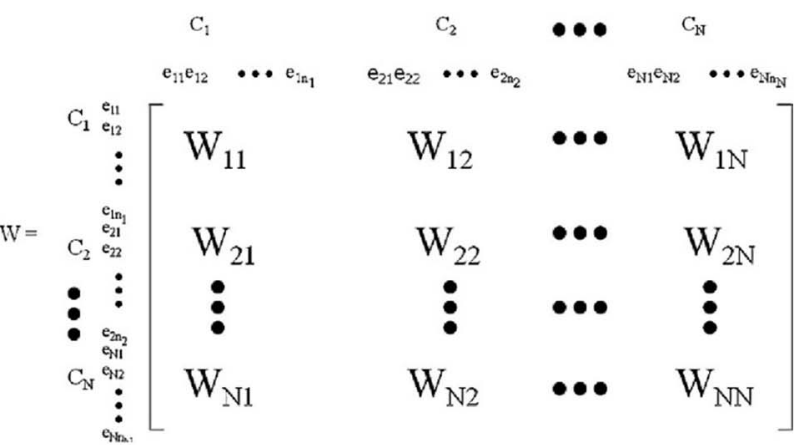

Where,

Wij is the Eigen vector of dominance weights

\section{Step $C$}

Super matrix calculation that is partitioned based on the cluster (factors) and pairwise comparison is applied to derive its elements (Figure 2). However, as it is a complex structure the super matrix consisting of $\mathrm{N}$ clusters that can be presented as follows; 
Where, $\mathrm{Ck}$ is the kth cluster $(\mathrm{k}=123 \ldots \mathrm{m})$ and each cluster $\mathrm{K}$ consists of $\mathrm{mk}$ items characterised by ek1,ek2,ek3 ...ekmk. The columns of Wij is derived from the pairwise comparison is known as the priority vector, which indicates each elements significance in the ith cluster with respect to an element in the jth cluster $[4,13]$.

\section{Step D}

In the final stage of the ANP methodology, computing the weight of the super-matrix through multiplying the matrix with factors priority should be considered. Therefore, by raising a weighted super matrix to the coming power the limited super-matrix is obtained. Consequently, constant numbers can be used to find one alternative as the solution to the problem. The details of steps applied in this study was presented in figure 3 .

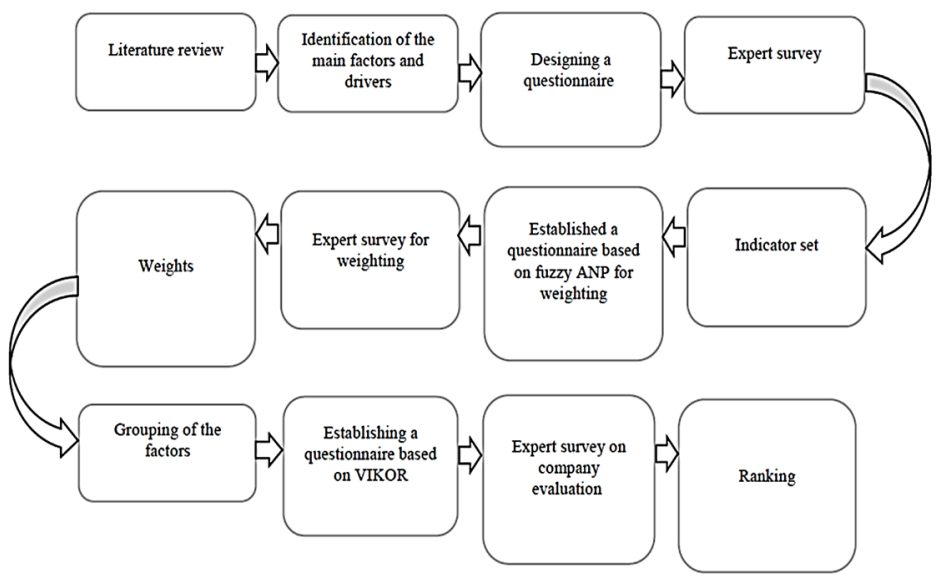

Figure 3. Steps needed for ranking the layers in ANP approach [4].

\section{RESULTS AND DISCUSSION}

The study developed a model for earthquake vulnerability assessment using expert-based approach. By considering the view of some specific earthquakes generated from the Aceh segment of the Great Sumatran Fault (Mw 7, Mw 6.5, and Mw 6) and some events from the Seulimuem segment with a constant magnitude ( $\mathrm{Mw}$ 6.5) we designed the model. The analysis produced a map of earthquake vulnerability for a particular scenario. The study showed that the strongest earthquake resulted from the great Sumatran fault and Seulimuem fault in Aceh segment would have the capacity to damage $47-75 \%$ of the Banda Aceh city's buildings and can able to destroy 5 to $26 \%$ of the population in almost all of the city's sub districts. The vulnerability map prepared for Banda Aceh city was classified into 5 classes based on the very high vulnerability to very low vulnerability. Therefore, from the resulted map it is clear that the map is accurate based on some factors such as building density, building quality, population and educated people. Therefore, the areas with very high vulnerability are characterised by very high population density, building density as well as educated people. Likewise, the very-low vulnerability can be found in coastal areas that are characterised by less population and buildings (Figure 4).

According to [3], the building frequency in Banda Aceh is calculated between 2 and $10 \mathrm{~Hz}$. Reference [4] described in their research about the vulnerability assessment. Specifically, the building frequency in the city is almost equal to the ground frequency and the ground shaking is very high in Banda Aceh. The resonance effect of buildings will increase the vibration when an earthquake of magnitude more than Mw 7 occurs. This enhanced the likelihood of buildings and engineering infrastructure collapse and this is the main cause of human injury and fatalities in Banda Aceh. The fundamental frequency of $0.6 \mathrm{~Hz}$ has been observed in Banda Aceh, which can significantly amplify the vibration throughout the city and may destroy the medium to high-rise buildings.

Therefore by considering the scenario of earthquake vulnerability the govt. of Indonesia should focus on; Development of environment and infrastructures that can improve environmental quality and control disaster mitigation. Increasing the level of protection, recovery of the critical area, conservation and utilisation of natural resources as a specific part of the developed city in order to improve the lifestyle. Pre-disaster, emergency responses, rehabilitation and reconstruction process should be the primary focus of state government as well as the national agencies.

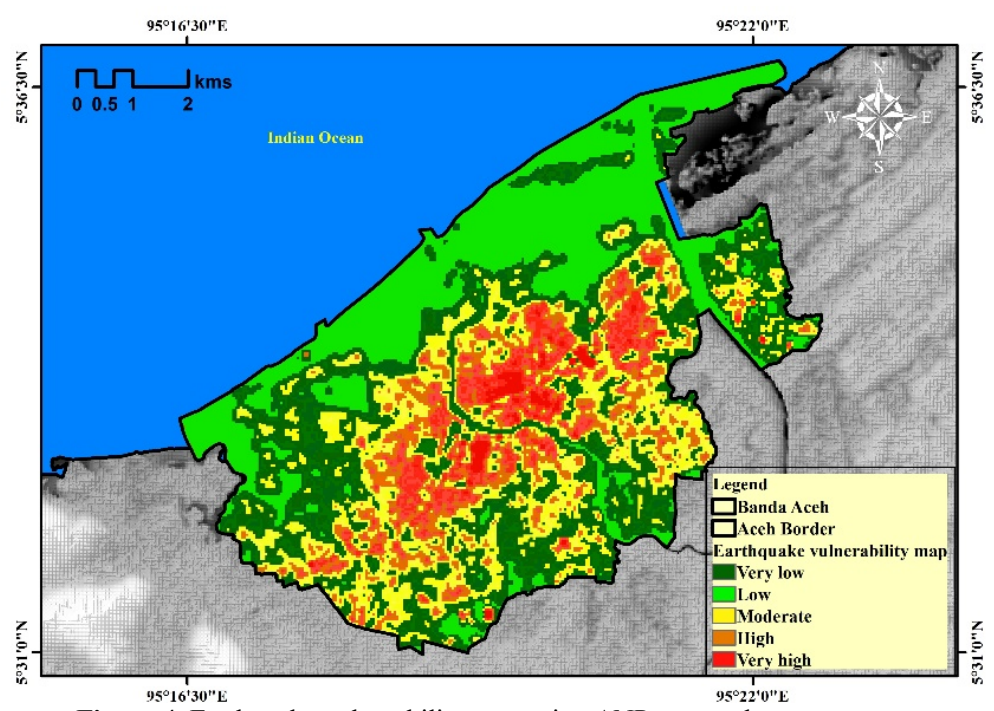

Figure 4. Earthquake vulnerability map using ANP approach 


\section{CONCLUSION}

Earthquake hazard in Indonesia is a very important section to consider for the future disaster mitigation management. According to the historical records, as indicated in this article that of pre-instrumental recorded earthquake activity provides the knowledge of more earthquakes that have been occurred from the last two decades in different parts of Indonesia which are now densely populated. Because of the high-density population, specifically in Sumatra, and due to the poor construction planning Indonesia is experiencing very high damage. There is a chance of getting major earthquakes during twenty-first century is reasonably high in Indonesia. However, before it happen, we should progress on planning to prevent the damages and casualties. In current time, due to rapid urbanization and densely population, as well as income growth, we should focus on developed construction by modifying the old cities to new one. We should develop new models or approach to mitigate or monitor the earthquake hazard and should be prepared. Building codes can be well integrated in the model by estimating the earthquake hazard, and the improved models with codes can help in substantially reducing the fatalities due to future earthquakes. Our approach of decision making for the earthquake vulnerability assessment can be applied for different regional as well as small-scale analysis. There are several reasons to believe in the efforts towards better earthquake vulnerability assessment and mitigation that can lead enormous benefits to community as well as the country. The analysis conducted in this paper produced a map showing the vulnerability of Banda Aceh. The proposed analysis and approach are able to provide key knowledge that can help in preparedness plans, including the building restoration as well as the targeted earthquake simulation development programs.

\section{ACKNOWLEDGMENT}

This research is funded by Centre for Advanced Modelling and Geospatial Information Systems, University of Technology Sydney, under grant: 323930, 321740.2232335 and 321740.2232357 .

\section{REFERENCE}

[1] M. Petersen, J. Dewey, S. Hartzell, C. Mueller, S. Hansen, A. Frankel and K. Rukstales, "Probabilistic seismic hazard analysis for Sumatra, Indonesia and across the southern Malaysian peninsula," Tectonophysics, vol. 390, pp. 141-158, 2001.

[2] M. Saatcioglu, A. Ghobarah and L. Nistor, "Performance of structures in Indonesia during the December 2004 great Sumatra earthquake and
Indian Ocean tsunami," Earthq. Spectra, vol. 22 (S3), pp. 295-319, 2006.

[3] B. Setiawan, and T. Saidi, "A preliminary results of sitespecific ground response analysis of Banda Aceh, Indonesia," The Proc. 2nd Annual International Conference Syiah Kuala University 2012 \& 8th IMT-GT Uninet Biosciences Conference Banda Aceh, 22-24 November 2012, 8, 2012.

[4] M. Alizadeh, I. Ngah, M. Hashim, B. Pradhan, and A. Pour, "A hybrid analytic network process and artificial neural network (ANP-ANN) model for urban earthquake vulnerability assessment". Remote Sensing, vol.10 (6), p.975, 2018.

[5] I. Rusydy, S. Arief, K. Munadi, and E. Melianda. "Disaster risk reduction policies and regulations in Aceh after the 2004 Indian Ocean Tsunami." In IOP Conference Series: Earth and Environmental Science, vol. 56, no. 1, p. 012022. IOP Publishing, 2017.

[6] S. Bambang, and W. B. Kusuma. "Banda Aceh-Indonesia Ground Response Analysis During the 2004 Indian Ocean Mega Earthquake." 2013.

[7] S. Anawat, M. Al'ala, M. Luthfi, and L.K. Comfort. "Assessing the tsunami mitigation effectiveness of the planned Banda Aceh Outer Ring Road (BORR), Indonesia." Natural Hazards and Earth System Sciences, vol. 19, no. 1, pp. 299-312, 2019.

[8] I. Hirokazu, Y. Takahashi, M. H. Pradono, P. Sukamdo, and R. Kurniawan. "Earthquake and tsunami questionnaires in Banda Aceh and surrounding areas." Disaster Prevention and Management: An International Journal, vol. 15, no. 1, pp. 21-30, 2006.

[9] H.R. Pourghasemi, B. Pradhan, and C. Gokceoglu. "Application of fuzzy logic and analytical hierarchy process (AHP) to landslide susceptibility mapping at Haraz watershed, Iran." Natural hazards 63, no. 2, pp. 965-996, 2012.

[10] O.F. Althuwaynee, B. Pradhan, H.J. Park, and J.H. Lee. "A novel ensemble bivariate statistical evidential belief function with knowledge-based analytical hierarchy process and multivariate statistical logistic regression for landslide susceptibility mapping". Catena, 114, pp.21-36, 2014.

[11] A.M. Youssef, B. Pradhan, and E. Tarabees. "Integrated evaluation of urban development suitability based on remote sensing and GIS techniques: contribution from the analytic hierarchy process". Arabian Journal of Geosciences, vol. 4(3-4), pp.463-473, 2011.

[12] O.F. Althuwaynee, B. Pradhan, and S. Lee. "A novel integrated model for assessing landslide susceptibility mapping using CHAID and AHP pair-wise comparison". International Journal of Remote Sensing, vol. 37(5), pp.1190-1209, 2016.

[13] H.R. Pourghasemi, M. Beheshtirad, and B. Pradhan. "A comparative assessment of prediction capabilities of modified analytical hierarchy process (M-AHP) and Mamdani fuzzy logic models using Netcad-GIS for forest fire susceptibility mapping". Geomatics, Natural Hazards and Risk, vol. 7(2), pp.861-885, 2016. 